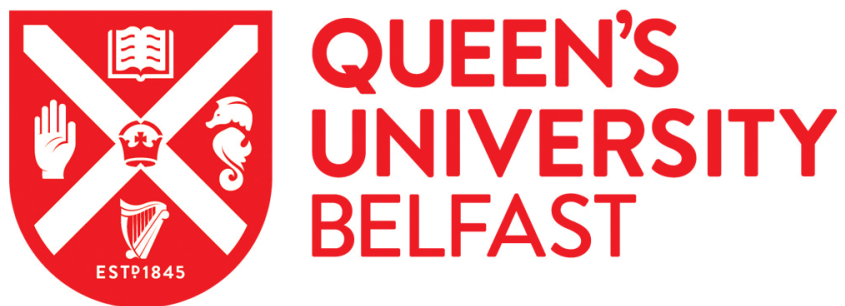

\section{Magnetic field generation using single-plate targets driven by kJ-ns class laser}

Kumar, D., Singh, S., Ahmed, H., Dudžák, R., Dostál, J., Chodukowski, T., Giuffrida, L., Hadjisolomu, P., Hodge, T., Juha, L., Krouský, E., Krůs, M., Li, Y., Lutoslawski, P., De Marco, M., Pfeifer, M., Rusiniak, Z., Skála, J., Ullschmeid, J., ... Kar, S. (2020). Magnetic field generation using single-plate targets driven by kJ-ns class laser. Plasma Physics and Controlled Fusion, 62(12), [125024]. https://doi.org/10.1088/1361-6587/abb617

Published in:

Plasma Physics and Controlled Fusion

Document Version:

Peer reviewed version

Queen's University Belfast - Research Portal:

Link to publication record in Queen's University Belfast Research Portal

Publisher rights

Copyright 2020 IOP. This work is made available online in accordance with the publisher's policies. Please refer to any applicable terms of use of the publisher.

\section{General rights}

Copyright for the publications made accessible via the Queen's University Belfast Research Portal is retained by the author(s) and / or other copyright owners and it is a condition of accessing these publications that users recognise and abide by the legal requirements associated with these rights.

Take down policy

The Research Portal is Queen's institutional repository that provides access to Queen's research output. Every effort has been made to ensure that content in the Research Portal does not infringe any person's rights, or applicable UK laws. If you discover content in the Research Portal that you believe breaches copyright or violates any law, please contact openaccess@qub.ac.uk. 


\title{
Magnetic field generation using single-plate targets driven by kJ-ns class laser
}

\author{
Deepak Kumar ${ }^{1,+}$, Sushil Singh ${ }^{1, \#}$, Hamad Ahmed ${ }^{2, \dagger}$, Roman \\ Dudžák $^{3,4}$, Jan Dostál ${ }^{3,4}$, Tomasz Chodukowski ${ }^{5}$, Lorenzo \\ Giuffrida $^{1}$, Prokopis Hadjisolomu ${ }^{2, \circ}$, Thomas Hodge ${ }^{2}$, Libor \\ Juha $^{3,4}$, Eduard Krouský ${ }^{3,4}$, Miroslav Krůs ${ }^{3}$, Yuanzhe Li $^{2}$, Piotr \\ Lutoslawski $^{1}$, Massimo De Marco ${ }^{1}$, Miroslav Pfeifer ${ }^{3,4}$, Zofia \\ Rusiniak $^{5}$, Jiří Skála ${ }^{4}$, Jiří Ullschmeid ${ }^{3}$, Tadeusz Pisarczyk ${ }^{5}$, \\ Marco Borghesi ${ }^{2}$, Satyabrata $\operatorname{Kar}^{2, *}$ \\ ${ }^{1}$ Institute of Physics of the CAS, ELI-Beamlines Project, Dolní Břežany 252 41, \\ Czech Republic \\ ${ }^{2}$ Centre for Plasma Physics, School of Mathematics and Physics, Queen's University \\ Belfast, Belfast, BT7 1NN, UK \\ ${ }^{3}$ Laser Plasma Department, Institute of Plasma Physics of the CAS, Prague 182 00, \\ Czech Republic \\ ${ }^{4}$ Department of Radiation and Chemical Physics, Institute of Physics of the CAS, \\ Prague 182 21, Czech Republic \\ ${ }^{5}$ Institute of Plasma Physics and Laser Microfusion, 01-497 Warsaw, Poland \\ E-mail: ${ }^{+}$deepak.kumar@eli-beams.eu; *s.kar@qub.ac.uk \\ \# Current addresses: Laser Plasma Department, Institute of Plasma Physics of the \\ CAS, Prague, Czech Republic \\ Department of Radiation and Chemical Physics, Institute of Physics of the CAS, \\ Prague, Czech Republic \\ † Current address: Central Laser Facility, STFC Rutherford Appleton Laboratory, \\ Didcot OX11 0QX, UK \\ - Current address: Institute of Physics of the CAS, ELI-Beamlines Project, Dolní \\ Břežany, Czech Republic
}

\begin{abstract}
Strong magnetic fields of upto $20 \mathrm{~T}$, corresponding to a current of tens of $\mathrm{kA}$ were produced in a coil connected to a single-plate of $\mathrm{cm}^{2}$ area irradiated by a $\mathrm{kJ}$-ns laser pulse. The use of such macroscopic plates protects the coil from plasma debris, while maintaining a strong magnetic field for a time-scale much longer than the laser pulse duration. By correlating the measured magnetic field in the coil to the number of electrons emitted from the interaction zone, we deduce that the target capacitance is enhanced by two orders of magnitude because of the plasma sheath in the proximity of the focal spot. Particle-in-cell simulations illustrate the dynamics of sheath potential and current flow through the coil to ground, thus closing the circuit due to the escape of laser-produced hot electrons from the target.
\end{abstract}


Submitted to: Plasma Phys. Control. Fusion 


\section{Introduction}

Externally applied magnetic fields have shown immense benefits in diverse laser plasma interaction experiments related to inertial confinement fusion[1, 2], laboratory astrophysics[3, 4], and for enhancing secondary sources of charged particles and radiation[5]. Consequently, there has been significant interest in developing innovative methods for enabling such experiments on large-scale laser facilities[6]. Two different technologies are currently used to provide strong magnetic fields for laser plasma experiments: (a) solenoids driven by conventional pulsed-power sources[7, 8], and (b) 'capacitor-coil' targets driven by kJ-ns class lasers[9-13]. External pulsed-power systems have been able to provide fields up to $40 \mathrm{~T}$ for the experiments over a magnetized volume of the order of $1 \mathrm{~cm}^{3}$. In contrast, the capacitor-coil targets have been able to generate much higher field strengths of the order of few hundred Teslas[12], albeit providing a much smaller magnetized volume of the order of $1 \mathrm{~mm}^{3}$. The ability to do so using an "all optical" configuration is a major advantage of the latter scheme.

Research on capacitor-coil targets has matured enough that successful application

of guiding relativistic electrons has been demonstrated recently[5, 14], while other potential applications are being explored[15]. However, models for the physical processes underpinning the operation of such targets[16] are yet to be fully developed and benchmarked with the experiments. A direct comparison of experimental results with the models is challenging because of the similar time scales on which several phenomena occur - for instance, the duration (ns) of the laser pulses used in such experiments is comparable to the plasma expansion time scale between the electrodes. Here we used a simplified target geometry (coil attached to a single-plate foil of $\mathrm{cm}^{2}$ surface area, as shown in fig. 1 (a)), in which the plasma expands freely into an open half space. A similar geometry was used by Zhu et al [17], however at much lower focused irradiance compared to the results shown here.

As the laser pulse irradiates the target, a small fraction of the hot electrons produced by the interaction are able to escape. While the majority of electrons are confined by a potential barrier, the few escaped electrons cause the target to behave as a positively charged capacitor. The charging process continues for the duration of the laser pulse, and for ns long interaction pulses the target potential can reach few times the temperature of the hot electrons produced by the laser[11, 18, 19]. Connecting this target to ground by a thin wire closes the circuit, leading high current to flow through the wire. The grounding wire can be designed to have a small loop to create a magnetized volume in its proximity. The data presented here shows that strong magnetic field in excess of $\sim 10$ $\mathrm{T}$, lasting over several ns was produced by these single-plate targets irradiated by $\sim 350$ ps long pulses at an irradiance of $\sim 3 \times 10^{16} \mathrm{Wcm}^{-2} \mu \mathrm{m}^{2}$. The magnetic field produced by the coil was measured by polarimetry at a distance of the order of the coil diameter. This enabled an accurate extrapolation to the field strength at the center of the coil from the plane of measurement (the ratio between the field strengths at the two planes was a relatively small factor in the range of $2-7$ ). The polarimetric measurements were 
performed simultaneously at two different wavelengths, both distant from the absorption band of the crystal used in the diagnostic, in order to map the temporal profile with higher accuracy and resolution over a limited number of shots. The large separation of about $\sim 3 \mathrm{~cm}$ between the laser interaction point to the coil prevented any damage and darkening of the crystal from X-ray and debris from the plasma.

The paper is organized as follows. Section 2 describes the experimental layout, the diagnostics and the targets used for the experiment. Section 3 describes the measured magnetic field and correlates it with other factors such as the total charge on the target, the time scale of discharge and the equivalent circuit impedances. Simulations carried out to study the target charging process are described in section 4 . Finally, section 5 concludes with a brief summary.

\section{Experimental Setup}

The experiment was conducted at the Prague Asterix Laser System (PALS) facility[21]. A schematic of the setup is shown in Fig. 1(a). The main beam from the Iodine laser, at wavelength $1.315 \mu \mathrm{m}$, pulse width $350 \mathrm{ps}$ at full width at half maximum (FWHM), delivered $600 \pm 50 \mathrm{~J}$ on target within a focal spot of diameter about $80 \mu \mathrm{m}$ FWHM. The peak focused irradiance on the target was $3 \times 10^{16} \mathrm{~W} \mathrm{~cm}{ }^{-2} \mu \mathrm{m}^{2}$. The target used in this campaign was a single plate of $28 \mathrm{~mm} \times 4 \mathrm{~mm}$, made of $50 \mu \mathrm{m}$ thick $\mathrm{Cu}$ foil. It was attached to the target mount using an insulating support. The foil was electrically grounded via a coil of $1.1 \mathrm{~mm}$ outer diameter, made of $\mathrm{Cu}$ wire with a square cross-section of $100 \mu \mathrm{m} \times 100 \mu \mathrm{m}$. The grounding wire, of a few cm total length, was electrically connected to the target mount. The connection between the coil, foil and ground were made by conducting silver lacquer, and the contact resistance was checked for each target before the shot. A Terbium Gallium Garnet (TGG) crystal of $\sim 500 \mu \mathrm{m}$ thick, $5 \mathrm{~mm}$ diameter, manufactured by Synoptics (a Northrop Grumman company), was placed parallel to the coil, as shown in Fig. 1(a). The distance of the front surface of the TGG to the center of the coil was varied from $0.3 \mathrm{~mm}$ to $1 \mathrm{~mm}$.

Magnetic field generated by the current in the coil induces a change in the polarization of the probe beams passing through the crystal. Polarimetry technique was used to measure the induced Faraday rotation of the probe beams in the TGG crystal. Two probe beams used in the experiment were: a frequency doubled $(2 \omega)$ beam derived from the main laser (pulse duration of $\sim 250$ ps FWHM, wavelength 655 $\mathrm{nm}$ ) and a synchronized Ti:Sa beam (pulse duration $\sim 50$ fs FWHM, at wavelength $810 \mathrm{~nm})[22]$. The latter beam was used for polarimetry imaging with the setup based on the design described by Pisarczyk et al [23]. The setup was modified to combine the probe beams upstream of the target, and then splitting them downstream using dichroic mirrors (see Fig. 1 (a)), following a Wollaston prism to split the probe beams into orthogonal polarizations. Two main features of the setup were (a) the use of a high

extinction ratio $\left(<5 \times 10^{-6}\right)$ Wollaston prism and the Glan-Taylor polarizer so that the signal-to-noise performance of the polarimetry system was mainly determined by 

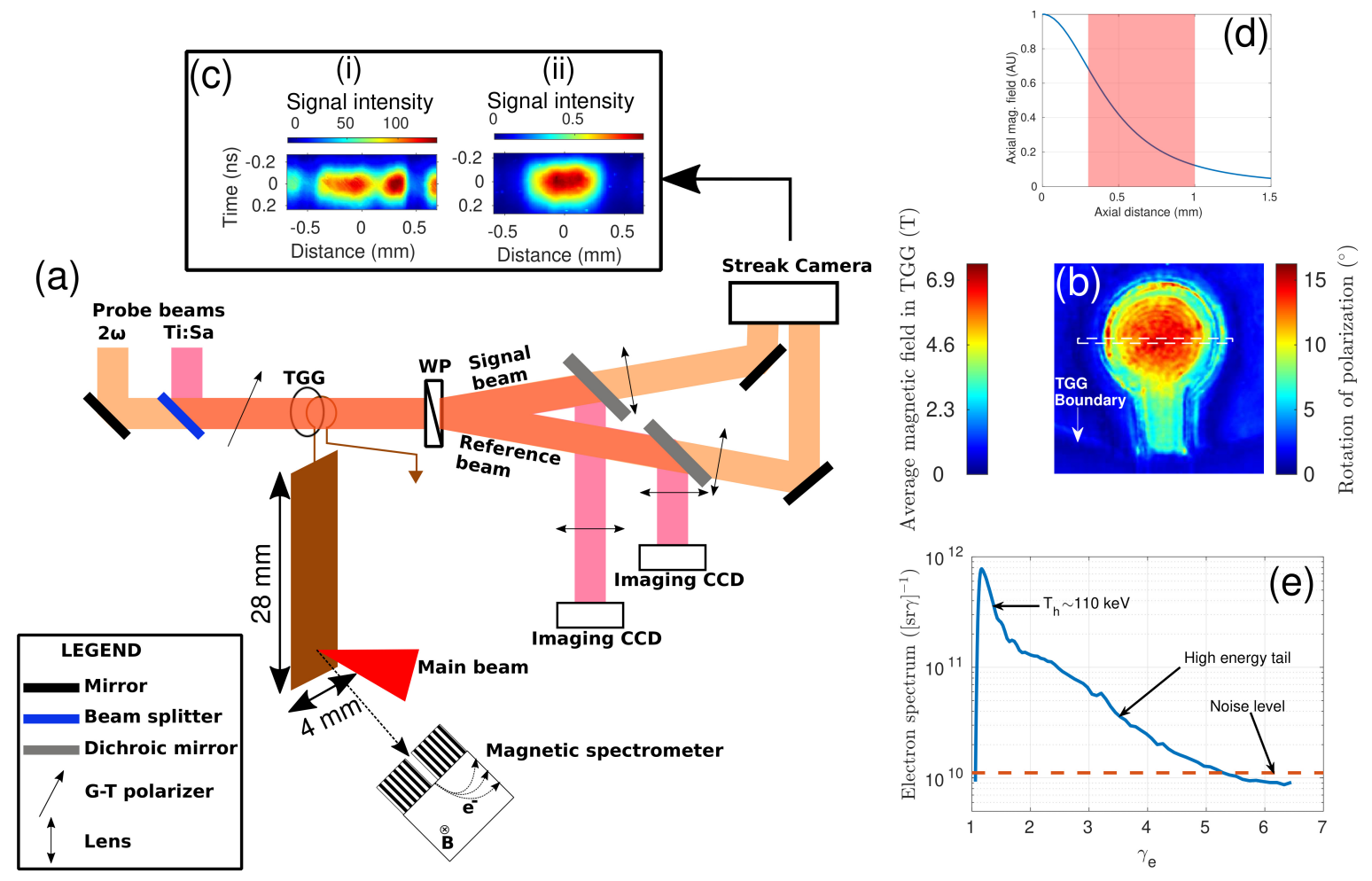

Figure 1. (Color online) (a) Schematic of the experimental setup. Interference filters and absorptive neutral density filters placed in front of the cameras are not shown in the schematic. (b) An example of measured polarization rotation in degrees (right colorbar) and the magnetic field across the plane of TGG (left colorbar) using the Ti:Sa probe beam. For this shot, the front surface of TGG crystal was $0.31 \mathrm{~mm}$ from the plane of the coil. (c) Example of measured data on the streak camera using the $2 \omega$ probe beam. The relative strength of the signal (ii) is about 2 orders of magnitude lower than that in the reference (i). Temporal extent of the signals is determined by the duration of the probe beam $(\sim 250 \mathrm{ps})$, which is much shorter than the time of evolution of the magnetic field. (d) Axial magnetic field from the coil as a function of axial distance, simulated by RADIA code[20]. The shaded red region indicates the range within which the front surface of TGG crystal was placed in various shots. (e) An example of measured electron spectrum as a function of electron relativistic factor $\left(\gamma_{e}\right)$.

the dynamic range of the imaging detectors, and, (b) except for a non-polarizing blast shield, there was no other optic in the beam path between the TGG crystal and the Wollaston prism. The second feature is essential since polarization based reflectivity of any optic before the Wollaston prism can introduce error in the measurements of change in rotation of polarization.

The Ti:Sa probe beam was imaged on CCD cameras and the $2 \omega$ probe beam was imaged on to a Hamamatsu streak camera (model number C7700, S1 photo cathode). Both imaging systems had a magnification of $\sim 2$. For highest sensitivity, the shots were taken with the axis of the Glan-Taylor polarizer orthogonal to the axis of the Wollaston prism, i.e., the polarimetry channels would have no signal unless the TGG crystal is exposed to a strong magnetic field introducing polarization rotation of the 
probe beams. The two-dimensional map of the rotation of the polarization vector was calculated using the relation $\tan ^{-1}(\sqrt{\text { signal image/reference image }})$, where the signal and reference images refer to the data measured in the respective cameras. An example of the rotation map inferred from the polarimetry imaging using the Ti:Sa beam is shown in Fig. 1(b). The dotted box in the figure represents the field of view through the slit of the streak camera imaging system. An example of this streaked polarimetry data using the $2 \omega$ probe beam is shown in Fig. 1(c), in which the wires of the coil at $\pm 0.5 \mathrm{~mm}$ are clearly visible. The signal shown in figure 1 (c-ii) is about two orders of magnitude lower than the reference (figure 1 (c-i)), which corresponds to a rotation angle of about $4.9^{\circ}$. The Verdet constant of TGG crystal used in this calculation was obtained from the data presented by Víllora et al [24]: $7032 \mathrm{deg} / \mathrm{T} / \mathrm{m}$ for $2 \omega$ and $4324 \mathrm{deg} / \mathrm{T} / \mathrm{m}$ for the Ti:Sa. When compared with other published calibrations of Verdet constant for the TGG crystals[25], a systematic error of $\sim 15 \%$ can be expected. The measured magnetic field in the TGG crystal was rescaled using the simulated field profile shown in Fig. 1 (d) to calculate the magnetic field at the center of the coil and the current through the coil. The simulated profile shown in figure 1(d) was obtained by using RADIA[20] code, which provided a magnetostatic model for the fields[26].

A magnetic electron spectrometer with a $1 \mathrm{~mm}$ opening aperture and a magnetic field of $\sim 0.1 \mathrm{~T}$ was used to measure the spectrum of fast electrons in the range of $0.2-3 \mathrm{MeV}$. The spectrometer was placed at an angle of $19^{0}$ from the target normal and covered a solid angle of approximately $10 \mu \mathrm{sr}$. Electrons in the spectrometer were detected using absolutely calibrated BAS-SR image plates from Fuji Film[27, 28]. The design of the spectrometer was such that the imaging plate (IP) detector had a "low visibility" orientation for reducing noise[29]. A typical electron spectrum measured in the experiment is shown in Fig. 1(e), which shows a Maxwellian-like bulk population with a high-energy tail. The hot electron temperature measured in various shots was in the range $80-120 \mathrm{keV}$, which agrees with the scaling $T_{h} \sim 250\left(I \lambda^{2}\right)^{\delta}$ reported with short pulse glass lasers $(\delta \sim 0.33[30])$. Here $T_{h}$ is the hot electron temperature in $\mathrm{keV}$ and $I \lambda^{2}$ is expressed in $10^{18} \mathrm{~W} \mathrm{~cm}^{-2} \mu \mathrm{m}^{2}$. The measured high energy tail with cutoff in the range of $2-3 \mathrm{MeV}$ is most likely due to electron acceleration by the plasma waves excited by parametric instabilities in the plasma[31].

\section{Experimental results and discussion}

The targets shown in Fig. 1(a) were shot multiple times with laser energy in the range of $550-650 \mathrm{~J}$ during the experimental campaign. The magnetic field and current flowing through the coil were inferred using the polarimetry data, which is shown in Fig. 2. The two-color polarimetry setup provides an increased confidence on the measurements and the calibration of the system. Temporal evolution of the magnetic field was mapped

by varying the delay of the probe beams with respect to the main beam across several shots. Since the time scale of the magnetic field evolution is of several ns, much larger than the duration of the $2 \omega$ probe beam, the data from the streak camera effectively 


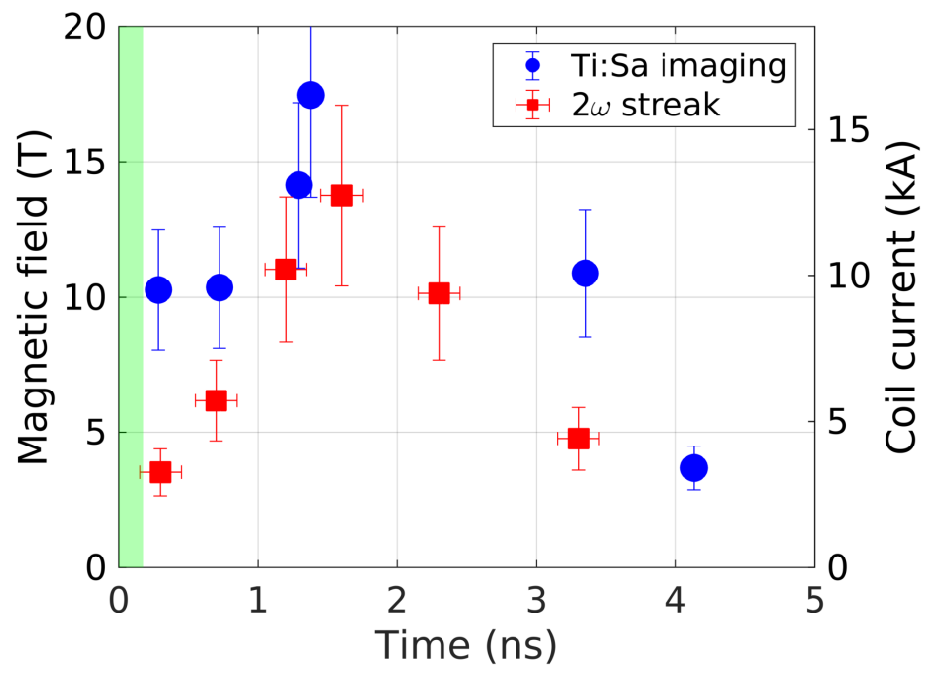

Figure 2. (Color online) Magnetic field at the center of the coil (left axis) and the current in the coil (right axis) as a function of time delay of the probing beams. The blue circles (red squares) represent the data inferred from Ti:Sa imaging ( $2 \omega$ streak). The error bars represent the systematic error in the Verdet constant of the TGG crystal and the noise of the detection system.

provides information at a given time instance. Zero delay corresponds to the arrival of the peak of the main laser pulse at the interaction point, at the same time as the arrival of the probe beams at the coil plane. The shaded green region in the figure has an extent of $175 \mathrm{ps}$, and corresponds to the HWHM (half width at half maximum) of the main pulse.

As can be seen from Fig. 2, magnetic field up to $\sim 20 \mathrm{~T}$ was produced by the coil, peaking around $1 \mathrm{~ns}$ after the laser pulse. The observed peak of the magnetic field corresponds to a strong current of $\sim 15 \mathrm{kA}$ flowing through the coil. The direction of the magnetic field indicates that the current in coil is unidirectional and flowing from the laser irradiated foil to ground via the coil. The total positive charge collected on the target can be estimated from the integral of the coil current with respect to time, which is about $30 \mu \mathrm{C}$. Charge conservation implies that about $1.4 \times 10^{14}$ electrons are ejected from the target, which is comparable with previous measurements of target return current with the Rogowski probe at the PALS laser system[32].

The temporal profile of the current indicates a very different scenario than the quasistationary approximation considered in the models typically used for the capacitor-coil targets[16]. A good approximation of the single-plate target's behavior shown in Fig. 2 would be to consider a fast charging process on the time scale of the laser pulse duration, followed by a slower current decay over a significantly long time scale of $\sim 4 \mathrm{~ns}$, most likely governed by the inductance of the circuit. The inductance of the target can be estimated as $\sim 70 \mathrm{nH}$, mainly due to the few cm length of the grounding wire and 28 mm length of the target plate[33].

The self-capacitance of the single-plate target is of the order of $0.5 \mathrm{pF}$ [34], which 
can be used to estimate the energy transfer from the laser pulse towards the charging of the target. For a measured target charge $Q=30 \mu \mathrm{C}$ and a target capacitance $C=0.5$ $\mathrm{pF}$, the electrostatic energy stored in the target would be $Q^{2} / 2 C=900 \mathrm{~J}$, which is higher than the laser energy $(\sim 600 \mathrm{~J})$ delivered to the target. Equally implausible is the estimated voltage on the target $V=Q / C=60 \mathrm{MV}$.

To resolve these inconsistencies, two conjectures are proposed - (a) the potential barrier that the fast electrons need to overcome to escape the target depends strongly on the electron temperature rather than the target's design and its dimensions (b) the capacitance of the target is significantly higher (by orders of magnitude) than its selfcapacitance because of the plasma sheath surrounding the laser interaction.

The first conjecture is similar to various models of target charging, where the fast electrons $[11,18,19]$ need to escape a potential barrier to charge the target, and the strength of the potential barrier depends primarily on the electron temperature. For our experiment, assuming a conversion efficiency from laser energy to fast electrons of $15 \%$, and a distribution of electrons with a temperature of $T_{e}=100 \mathrm{keV}$, we estimate a charge of $Q=30 \mu \mathrm{C}$ escaping the potential barrier of $\sim 5 T_{e}$. For this estimated target potential, the target capacitance should be $C \sim 60 \mathrm{pF}$, which forms the basis for our second conjecture.

Next, we consider the energy dissipation in the system. The initial electrostatic energy stored in the target is $E_{\mathrm{es}}=Q^{2} / 2 C \sim 8 \mathrm{~J}$, which corresponds to $\gtrsim 1 \%$ of the initial laser energy. The average resistance of the equivalent electrical circuit can be estimated as $R=E_{\mathrm{es}} / \int_{0}^{\infty} I^{2} d t \sim 25 \Omega$, where $I$ is the current flowing in the circuit. While such an anomalously high resistance cannot be explained by Spitzer resistivitiy of the plasma, or the Ohmic resistivity of the $\mathrm{Cu}$ wire, it is consistent with the experimentally observed non-oscillatory current i.e., circuit was close to being critically damped. The time scale over which the target discharges is $\sim 4 \mathrm{~ns}$, as seen in fig. 2 , which is the same order as the response time of the equivalent circuit, $2 \pi \sqrt{L C} \sim 10 \mathrm{~ns}$, while considering the enhanced target capacitance.

As suggested by simulation in the following section, for high energy long pulse lasers (kJ - ns class) the plasma sheath can cause anomalously high target capacitance. While the focal spot diameter for the current experiment was about $80 \mu \mathrm{m}$, the plasma expands to a radius $r \approx 500 \mu \mathrm{m}$ during the duration of the pulse (350 ps FWHM). Assuming an electron temperature and density near the target to be $1 \mathrm{keV}$ and $10^{19}$ $\mathrm{cm}^{-3}$ respectively, the Debye length can be estimated of the order of $\lambda_{D} \approx 0.1 \mu \mathrm{m}[35,36]$. Since the plasma shields the electric potential of the target over a distance of the order of the Debye length, the capacitance of the target in our experiment can be estimated to be $\epsilon_{0} \pi r^{2} / \lambda_{D} \approx 70 \mathrm{pF}$, where $\epsilon_{0}$ is the permittivity of free space. Such high target capacitance of the order of $100 \mathrm{pF}$ has been estimated in direct drive fusion experiments, and attributed to the plasma sheath around the target[37]. Goyon et al [10] have also suggested a much higher capacitance of the target in order to explain the measured time scale of magnetic field evolution in their experiment. 

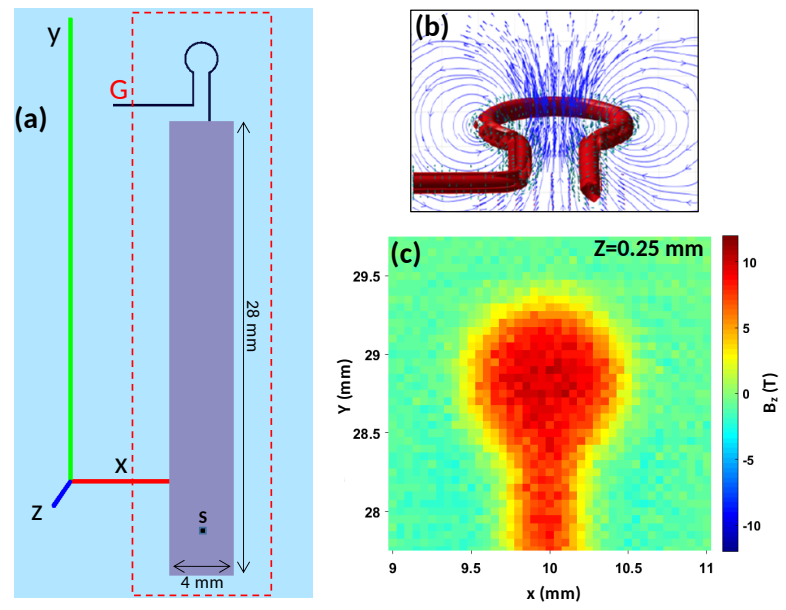

Figure 3. (Color online) (a) Schematic of the setup in VSIM simulation studying magnetic field generation by the target used in the experiment. (b) 3D vector plot illustrating magnetic field lines around the coil. (c) 2D map of the $z$-component of magnetic field $\left(B_{z}\right)$ across the plane $\Delta z=0.25 \mathrm{~mm}$ behind the plane of the coil.

\section{Simulations}

The dynamics of target charging was modeled by 3D simulation employing the hybrid Multiphysics-particle-in-cell code VSIM[38, 39]. The target shown in Fig. 1(a) was modelled as a perfect electrical conductor. While one end of the coil was connected to the target foil, the grounding of the other end of the coil was modeled by extending the wire past the boundary of the simulation box, marked as "G" in Fig. 3(a). The simulated volume was $8 \mathrm{~mm} \times 36 \mathrm{~mm} \times 5 \mathrm{~mm}$ with a grid size of $50 \mu \mathrm{m}$ in all directions. The boundaries of the simulation box were open for fields and particles crossing it. The electron source of size $500 \mu \mathrm{m} \times 500 \mu \mathrm{m}$ was placed on the plate, at the laser focus marked as "S" in Fig. 3(a). Electron macroparticles were loaded into the source with a Gaussian temporal profile of $350 \mathrm{ps}$ FWHM, peaking at $0.5 \mathrm{~ns}$ after the start of the simulation. The macroparticle energy spectrum reproduced the electron spectrum shown in Fig. 1(e). The total energy of electrons ejected from the target over a period of 1 ns was $100 \mathrm{~J}$, which corresponds to $\sim 16 \%$ conversion efficiency from laser to electrons. The total charge injected at the source was $164 \mu \mathrm{C}$.

At earlier times in the simulation, corresponding to the charging process, electrons with energy greater than the target potential propagate directly to the simulation boundary as shown in Fig. 4 (a), and are removed from the simulation. The net charge accumulated on the target is neutralized by a return current through the coil. As an example, magnetic field around the coil from this return current is shown in Fig. 3 (b) and (c), which resembles well with the experimental results shown in figure 1(b). The low energy electrons, which are trapped by the target potential spread over the target surface and create a thin sheath, as can be seen in Fig. 4(a) and (b). The spreading of charge along the foil happens nearly at the speed of light[40], as seen in figure 4 (a). The electron sheath around the target helps shielding the target potential effectively with 

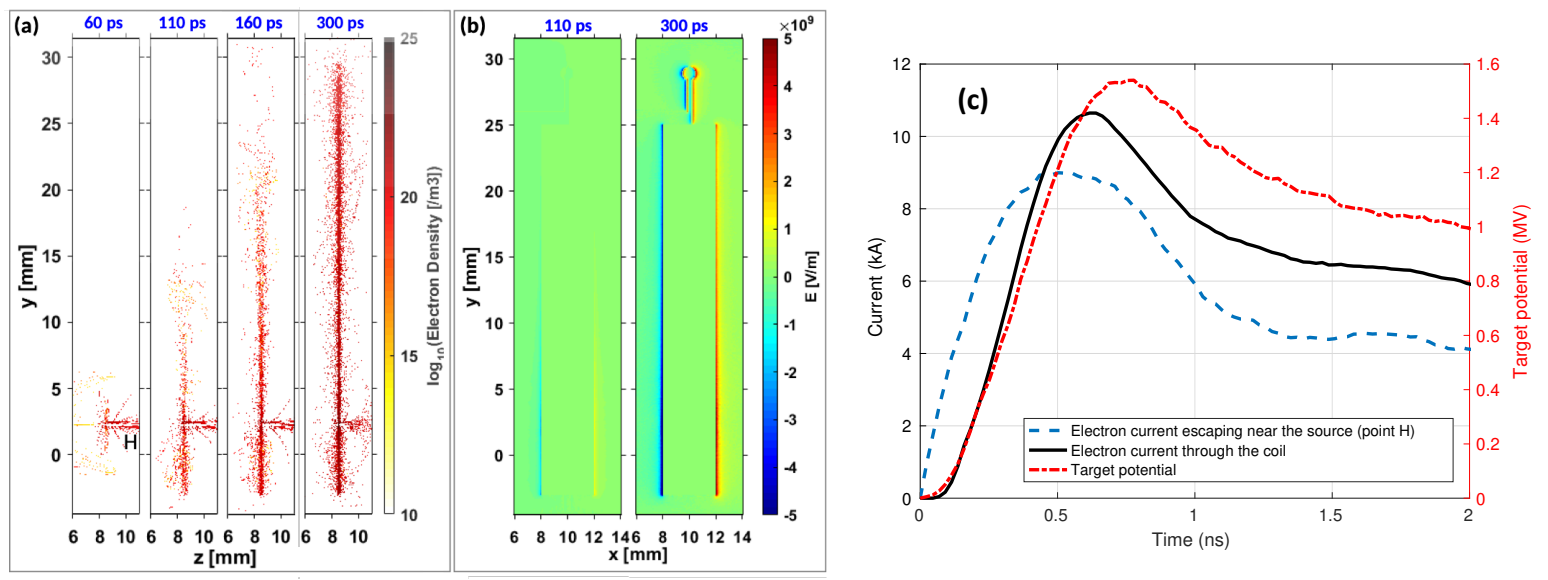

Figure 4. (Color online) (a) Electron density distribution across the mid-section of the target at different times, as labelled above each frame. The fast electrons escape near the region marked as " $\mathrm{H}$ ", whereas the trapped electrons form a Debye sheath that enhances the target capacitance. (b) 2D map of the $x$ component of the electric field across the foil plane at two different times, as labeled above each frame. The electric field decays exponentially outside the target, effectively shielding the target potential within a scale length of $\sim 120 \mu \mathrm{m}$. (c) Temporal evolution of the current through the coil (black line) in comparison with the current of electrons escaping from the simulation box near the point "H" marked in Fig. 4 (a) (dashed blue line). While the former is calculated from the magnetic field at the centre of the coil, the latter is calculated by subtracting the electron current crossing the boundary near the ground wire (at ' $G$ ') from the electron current escaping the entire simulation box. Evolution of the target potential as a function of time is shown in dotted red line, which was estimated at different time instants from the electric field shown in (b).

a small Debye length of $\lambda_{D} \sim 120 \mu \mathrm{m}$, which enhances the capacitance of the target by orders of magnitude. For instance, the electric field at $t=300 \mathrm{ps}$, soon after the target is fully engulfed by the electron sheath, is of the order of $5 \times 10^{9} \mathrm{~V} / \mathrm{m}$, as shown in Fig. 4(b). This corresponds to a surface charge density of about $4.5 \mu \mathrm{C} / \mathrm{cm}^{2}$. The accumulated charge on the plate is therefore $\sim 9 \mu \mathrm{C}$, which is of the same order as the measured target charge in the experiment. The target potential at $300 \mathrm{ps}$ is of the order of $V=600 \mathrm{kV}$, as can be seen in Fig. 4(c), which, for a total accumulated charge of $Q=9 \mu \mathrm{C}$ implies a target capacitance $C=Q / V \sim 15 \mathrm{pF}$. This is consistent with the capacitance if calculated directly considering the Debye shielding, $C=\epsilon_{0} A / \lambda_{D} \sim 15 \mathrm{pF}$, where $\epsilon_{0}$ is the vacuum permittivity, $A \sim 2 \mathrm{~cm}^{2}$ is the total surface area of the foil target, and $\lambda_{D} \sim 120 \mu \mathrm{m}$ as discussed above. The effect of sheath is best illustrated by the fact that in the absence of a sheath, a target charge of $9 \mu \mathrm{C}$ would imply an unrealistic target potential of $9 \mu \mathrm{C} / 0.5 \mathrm{pF}=18 \mathrm{MV}$, where $0.5 \mathrm{pF}$ is the self-capacitance of the target in the absence of a sheath i.e., in vacuum. The total charge transported with the return current (given by the integral of the black line in Fig. 4(c)) is about $15 \mu \mathrm{C}$, which is similar to the charge escaped from the source (blue line), and corresponds to a small fraction $(\sim 10 \%)$ of the total charge ejected from the source. Therefore, the large number of electrons trapped around the target screen its potential by the Debye 
sheath and facilitate more energetic electrons to escape. The inferred capacitance from the target is significantly higher than the target's self-capacitance and agrees with our assessment based on the experimental data as discussed in section 3 .

It should be noted that the simulation does not include collisional losses, ohmic heating of the target and subsequent cooling down of the electron population. A complete model of the experiment should simulate the laser plasma interaction and also include a self-consistent formulation of plasma evolution in presence of ions, with a dynamically evolving hot electron spectrum governed by spatio-temporal profile of the laser pulse. This would entail extensive plasma simulations which are beyond the scope of the current paper. However, despite being a simplified model, the simulation clearly demonstrates the salient features in the experimental data, indicating the enhanced target capacitance by the sheath.

\section{Conclusion}

In summary, the paper presents experimental results on magnetic field generation up to $20 \mathrm{~T}$, by the return current that neutralizes single-plate targets with an extent of few $\mathrm{cm}^{2}$ cross-section irradiated by a kJ-ns class laser. The experiment was performed at sub-relativistic intensities and it was suggested that the effective target capacitance was of the order of tens of pF, i.e., substantially higher than the self-capacitance of the target estimated from its size. The simple design of using a single plate of large dimension enables the magnetized volume within the coil to be better shielded from the adverse extraneous effects of kJ-ns class laser interaction. It also allows significant flexibility in deploying such targetry in high energy density experiments. These targets can be irradiated by multiple lasers from different directions, either simultaneously or by staging in time, which may lead to significant up-scaling of the field magnitude and duration. Thus, such targets will be beneficial to many future applications requiring strong magnetic fields lasting for tens of ns.

\section{Acknowledgment}

We thank Prof. Vladimir Tikhonchuk for multiple helpful discussions and comments. The results of the project LQ1606 were obtained with the financial support of the Czech Ministry of Education, Youth and Sports as part of targeted support from the National Programme of Sustainability II. The work was also supported by the project Advanced research using high intensity laser produced photons and particles (CZ.02.1.010.00.016_019/0000789) from European Regional Development Fund (ADONIS) and by Grant Agreement No.: 654148 (LaserLab Europe IV). L.J., J.D., R.D., M.P., M.K., S.S. and J.S. acknowledge a financial support from the Czech Ministry of Education, Youth and Sports within grants LTT17015, LM2015083 and CZ.02.1.010.00.016_0130001552 (EF16_0130001552). Authors also acknowledge funding support from EPSRC UK [EP/J002550/1-Career Acceleration Fellowship held by S.K., 
EP/L002221/1, EP/K022415/1, and EP/P010059/1].

\section{References}

[1] Chang P Y, Fiksel G, Hohenberger M, Knauer J P, Betti R, Marshall F J, Meyerhofer D D, Séguin F H and Petrasso R D 2011 Phys. Rev. Lett. 107(3) 035006

[2] Froula D H, Ross J S, Pollock B B, Davis P, James A N, Divol L, Edwards M J, Offenberger A A, Price D, Town R P J, Tynan G R and Glenzer S H 2007 Phys. Rev. Lett. 98(13) 135001

[3] Albertazzi B, Ciardi A, Nakatsutsumi M, Vinci T, Béard J, Bonito R, Billette J, Borghesi M, Burkley Z, Chen S N, Cowan T E, Herrmannsdörfer T, Higginson D P, Kroll F, Pikuz S A, Naughton K, Romagnani L, Riconda C, Revet G, Riquier R, Schlenvoigt H P, Skobelev I Y, Faenov A, Soloviev A, Huarte-Espinosa M, Frank A, Portugall O, Pépin H and Fuchs J 2014 Science 346 325-328 ISSN 0036-8075

[4] Fiksel G, Fox W, Bhattacharjee A, Barnak D H, Chang P Y, Germaschewski K, Hu S X and Nilson P M 2014 Phys. Rev. Lett. 113(10) 105003

[5] Bailly-Grandvaux M, Santos J, Bellei C, Forestier-Colleoni P, Fujioka S, Giuffrida L, Honrubia J, Batani D, Bouillaud R, Chevrot M et al. 2018 Nature communications 9102

[6] Fournier K B and Moody J D 2016 Report on the b-fields at nif workshop held at llnl october 12-13, 2015 Tech. rep. Lawrence Livermore National Laboratory

[7] Fiksel G, Agliata A, Barnak D, Brent G, Chang P Y, Folnsbee L, Gates G, Hasset D, Lonobile D, Magoon J, Mastrosimone D, III M J S and Betti R 2015 Review of Scientific Instruments 86016105

[8] Albertazzi B, Béard J, Ciardi A, Vinci T, Albrecht J, Billette J, Burris-Mog T, Chen S N, Silva D D, Dittrich S, Herrmannsdörfer T, Hirardin B, Kroll F, Nakatsutsumi M, Nitsche S, Riconda C, Romagnagni L, Schlenvoigt H P, Simond S, Veuillot E, Cowan T E, Portugall O, Pépin H and Fuchs J 2013 Review of Scientific Instruments 84043505

[9] Daido H, Miki F, Mima K, Fujita M, Sawai K, Fujita H, Kitagawa Y, Nakai S and Yamanaka C 1986 Phys. Rev. Lett. 56(8) 846-849

[10] Goyon C, Pollock B B, Turnbull D P, Hazi A, Divol L, Farmer W A, Haberberger D, Javedani J, Johnson A J, Kemp A, Levy M C, Grant Logan B, Mariscal D A, Landen O L, Patankar S, Ross J S, Rubenchik A M, Swadling G F, Williams G J, Fujioka S, Law K F F and Moody J D 2017 Phys. Rev. E 95(3) 033208

[11] Courtois C, Ash A D, Chambers D M, Grundy R A D and Woolsey N C 2005 Journal of Applied Physics 98054913

[12] Santos J J, Bailly-Grandvaux M, Giuffrida L, Forestier-Colleoni P, Fujioka S, Zhang Z, Korneev P, Bouillaud R, Dorard S, Batani D, Chevrot M, Cross J E, Crowston 
R, Dubois J L, Gazave J, Gregori G, d'Humières E, Hulin S, Ishihara K, Kojima S, Loyez E, Marquès J R, Morace A, Nicolaï P, Peyrusse O, Poyé A, Raffestin D, Ribolzi J, Roth M, Schaumann G, Serres F, Tikhonchuk V T, Vacar P and Woolsey N 2015 New Journal of Physics 17083051

[13] Chien A, Gao L, Ji H, Yuan X, Blackman E G, Chen H, Efthimion P C, Fiksel G, Froula D H, Hill K W, Huang K, Lu Q, Moody J D and Nilson P M $2019 \underline{\text { Physics }}$ of Plasmas 26062113

[14] Sakata S, Lee S, Morita H, Johzaki T, Sawada H, Iwasa Y, Matsuo K, Law K F F, Yao A, Hata M, Sunahara A, Kojima S, Abe Y, Kishimoto H, Syuhada A, Shiroto T, Morace A, Yogo A, Iwata N, Nakai M, Sakagami H, Ozaki T, Yamanoi K, Norimatsu T, Nakata Y, Tokita S, Miyanaga N, Kawanaka J, Shiraga H, Mima K, Nishimura H, Bailly-Grandvaux M, Santos J J, Nagatomo H, Azechi H, Kodama R, Arikawa Y, Sentoku Y and Fujioka S 2018 Nature Communications 93937 ISSN 2041-1723

[15] Arefiev A, Toncian T and Fiksel G 2016 New Journal of Physics 18105011

[16] Tikhonchuk V T, Bailly-Grandvaux M, Santos J J and Poyé A 2017 Phys. Rev. E 96(2) 023202

[17] Zhu B J, Li Y T, Yuan D W, Li Y F, Li F, Liao G Q, Zhao J R, Zhong J Y, Xue F B, He S K, Wang W W, Lu F, Zhang F Q, Yang L, Zhou K N, Xie N, Hong W, Wei H G, Zhang K, Han B, Pei X X, Liu C, Zhang Z, Wang W M, Zhu J Q, Gu Y Q, Zhao Z Q, Zhang B H, Zhao G and Zhang J 2015 Applied Physics Letters 107261903

[18] Pearlman J S and Dahlbacka G H 1977 Applied Physics Letters 31 414-417

[19] Poyé A, Dubois J L, Lubrano-Lavaderci F, D'Humières E, Bardon M, Hulin S, Bailly-Grandvaux M, Ribolzi J, Raffestin D, Santos J J, Nicolaï P and Tikhonchuk V 2015 Phys. Rev. E 92(4) 043107

[20] http://www.esrf.eu/accelerators/groups/insertiondevices/software/radia retrieved 2019

[21] Jungwirth K, Cejnarova A, Juha L, Kralikova B, Krasa J, Krousky E, Krupickova P, Laska L, Masek K, Mocek T, Pfeifer M, Präg A, Renner O, Rohlena K, Rus B, Skala J, Straka P and Ullschmied J 2001 Physics of Plasmas 8 2495-2501

[22] Dostal J, Dudzak R, Pisarczyk T, Pfeifer M, Huynh J, Chodukowski T, Kalinowska Z, Krousky E, Skala J, Hrebicek J, Medrik T, Golasowski J, Juha L and Ullschmied J 2017 Review of Scientific Instruments 88045109

[23] Pisarczyk T, Gus'kov S Y, Dudzak R, Chodukowski T, Dostal J, Demchenko N N, Korneev P, Kalinowska Z, Kalal M, Renner O, Smid M, Borodziuk S, Krousky E, Ullschmied J, Hrebicek J, Medrik T, Golasowski J, Pfeifer M, Skala J and Pisarczyk P 2015 Physics of Plasmas 22102706

[24] Víllora E G, Molina P, Nakamura M, Shimamura K, Hatanaka T, Funaki A and Naoe K 2011 Applied Physics Letters 99011111 
[25] Barnes N P and Petway L B 1992 josa B 9 1912-1915

[26] Singh S, Ahmed H, Dudzak R, Dostal J, Chodukowski T, Giuffrida L, Hadjisolomu P, Hodge T, Hrebicek J, Juha L, Kalinowska Z, Krousky E, Krus M, Lutoslawski P, Marco M D, Pfeifer M, Skala J, Ullschmeid J, Pisarczyk T, Borghesi M, Kumar D and Kar S 2016 Magnetic field generation from a foil-coil target using kj-ns class lasers (43 ${ }^{\text {rd }}$ EPS Conference on Plasma Physics) p2.102

[27] Singh S, Slavicek T, Hodak R, Versaci R, Pridal P and Kumar D 2017 Review of Scientific Instruments 88075105

[28] Zeil K, Kraft S D, Jochmann A, Kroll F, Jahr W, Schramm U, Karsch L, Pawelke J, Hidding B and Pretzler G 2010 Review of Scientific Instruments 81013307

[29] Gotchev O V, Brijesh P, Nilson P M, Stoeckl C and Meyerhofer D D 2008 Review of Scientific Instruments 79053505

[30] Beg F N, Bell A R, Dangor A E, Danson C N, Fews A P, Glinsky M E, Hammel B A, Lee P, Norreys P A and Tatarakis M 1997 Physics of Plasmas 4 447-457

[31] Rousseaux C, Amiranoff F, Labaune C and Matthieussent G 1992 Physics of Fluids B: Plasma Physics 4 2589-2595

[32] Cikhardt J, Krása J, De Marco M, Pfeifer M, Velyhan A, Krouský E, Cikhardtová B, Klír D, Řezáč K, Ullschmied J, Skála J, Kubeš P and Kravárik J 2014 Review of Scientific Instruments 85103507

[33] Terman F E 1943 Radio Engineer's Handbook (McGraw-Hill Book Comapny, Inc.)

[34] Reitan D K and Higgins T J 1957 Transactions of the American Institute of Electrical Engineers, Part I: Communication and Electronics 75 761-766 ISSN 0097-2452

[35] Pisarczyk T, Gus'kov S, Renner O, Demchenko N, Kalinowska Z, Chodukowski T, Rosinski M, Parys P, Smid M, Dostal J and et al 2015 Laser and Particle Beams $33221-236$

[36] Huba J D 2016 NRL Plasma Formulary

[37] Sinenian N, Zylstra A B, Manuel M J E, Rinderknecht H G, Frenje J A, Séguin F H, Li C K, Petrasso R D, Goncharov V, Delettrez J, Igumenshchev I V, Froula D H, Stoeckl C, Sangster T C, Meyerhofer D D, Cobble J A and Hicks D G 2012 Applied Physics Letters 101114102

[38] Nieter C and Cary J R 2004 Journal of Computational Physics 196448 - 473 ISSN 0021-9991

[39] Vsim, www.txcorp.com for information on electromagnetic and electrostatic simulation with vsim software. retrieved 2019

[40] Quinn K, Wilson P A, Cecchetti C A, Ramakrishna B, Romagnani L, Sarri G, Lancia L, Fuchs J, Pipahl A, Toncian T, Willi O, Clarke R J, Neely D, Notley M, Gallegos P, Carroll D C, Quinn M N, Yuan X H, McKenna P, Liseykina T V, Macchi A and Borghesi M 2009 Phys. Rev. Lett. 102(19) 194801 